\title{
OBRAS EN LAS IGLESIAS DE ESPITA Y MAMA, YUCATÁN, SEGUN UNOS DOCUMENTOS DE 1738
}

Por Jorge Luján Muñoz

\section{⿷. Introducción}

La historia de la arquitectura en el periodo de la dominación en Hispanoamérica está todavía llena de lagunas de información: para la mayoría de los edificios, especialmente los del área rural, nos hacen falta datos no sólo sobre sus autores sino incluso las fechas de las construcciones y reedificaciones que nos permitan ir estableciendo un panorama y secuencia más intelegible. De ahí la necesidad de dar a conocer cualquier documentación que permita fechar, aunque sea parcialmente, una iglesia.

En el Archïwo General de Indias, Sevilla (de aquí en adelante citado simplemente $A G I$ ), en la sección quinta, legajo "México 892", hemos encontrado información que nos permite fechar la construcción y finalización de dos iglesias de Yucatán, las de los pueblos de Espita y Mama. Se trata de dos cartas, una del gobernador don Manuel Salzedo y otra del obispo doctor don Francisco Pablo Matos de Coronado, escritas, respectivamente, el 7 y el 14 de julio de 1738. Su contenido y redacción es similar, con pacos datos en una que no estén en la otra, y dada la buena relación que se sabe existía entre ambos, es dable pensar que las escribieron de acuerdo y conociendo cada uno el contenido de lo. que diría el otro.

Se refieren a las obras que se estaban realizando en las iglesias de los dos pueblos y van dirigidas al rey para informarle, en cumplimiento de real cédula de 26 de marzo de 1737 , sobre la "reedificación" de las iglesias de los pueblos de indios de esa provincia. Por texto de la carta del prelado se ve que éste se había dirigido previamente al monarca -en 22 de abril de 1736- sobre este tema que le preocupaba, haciéndole ver "el reparo que necesitan las iglesias... que en gran parte se hallan cubiertas de paja", y le proponía un procedimiento para hacerlo sin recargo de la Real Hacienda ni gravamen de los encomenderos. Los indios del pueblo interesado se encargarían de la labor, aliviándolos en sus servicios y trabajos de otro tipo. Como respuesta, el rey ordenó, por la citada real cédula, que el obispo se pusiera de acuerdo con el gobernador y que ambos informaran sobre el medio que les pareciere "más practicable". 
Ambos funcionarios se llevaban bien, desde que habian llegado juntos en el viaje para hacerse cargo de sus nuevos destinos. De manera que no fue difícil, en colaboración, encontrar el medio de resolver el problema de las iglesias, que tanto preocupaba al eclesiástico, que simultáneamente se llevaran a cabo obras en dos o tres iglesias, relevando a los indios del partido que se trataba, sin darles ayuda de otros en los de doscientas mantas parą arriba, y en los que no llegasen a ese número proporcionándoselas de los pueblos cercanos. El primero era el caso de Espita, el segundo el de Mama.

Es interesante señalar el reconocimiento que hacen ambos, especialmente el obispo, de lo recargado de trabajos que estaban los indios, y que sólo al relevarlos de ellos se superaría la resistencia ("horror") que manifestaban a construir sus iglesias, y que el edificio material no resultara en su "ruina espiritual".

Dada la similitud de contenido de ambas cartas, he preferido transcribir sólo la del obispo, aprovechando la presentación y comentario inicial para incorporar aquellos datos de la del gobernador que no aparecen en la del prelado.

Para una mejor comprensión del documento, lo antecedo de un estudio en que se ubica no sólo éste y su autor sino se hace referencia a la situa. ción general de las iglesias en Yucatán, al entorno histórico-social y a las obras realizadas en ambos templos.

\section{Situación general de las iglesias de Yucatán en la época}

La situación de las iglesias de Espita y Mama no era una excepción con respecto a la mayoría de las iglesias rurales de Yucatán. Como ya vimos, el obispo, luego de su visita pastoral, dice con desaliento que la mayoría necesitaban reparo y que se hallaban cubiertas de paja.

Por otra carta del mismo legajo sabemos que la situación ya había preocupado a otro gobernador, como para mencionarla en una de fecha 15 de abril de 1732. Dice el gobernador don Antonio de Figueroa que desde que tomó posesión - lo que había verificado el 24 de diciembre de 1725 - se había dedicado cuanto le había sido posible por "la cortedad de aquel país" al adelantamiento de las fábricas, tanto en fortificaciones como de una iglesia -que desafortunadamente en esa carta no identifica, y que probablemente se refiera a Mérida- que halló "arruinada". Señala que de ellas "he tenido oportunidad de pintar liensos, sujetas a sus mensuras [de que] hago remisión..." Desafortuna. 
damente, en el $A G l$ no aparecen estampas ni planos que correspondan a las fechas, por lo que parece que se han perdido estos que podrían haber sido extraordinarios documentos visuales para la historia de la arquitectura en Yucatán.

Puede ser que la información proporcionada por el gobernador Figueroa haya producido la real orden de 18 de diciembre de 1734, que cita el obispo Matos de Coronado en su carta.

El gobernador y el obispo conciben un plan a largo plazo, en el que durante veinte años, trabajando simultáneamente sólo en dos o a lo sumo en tres iglesias, se irían reparando y mejorando las iglesias de los pueblos de indios que se encontraban en mal estado.

Desconozco en qué medida se llevaría a cabo lo que proponían. Ya el prelado reconoce lo difícil que sería cuando dice que durante ese tiempo se mudaría el gobierno de la provincia al menos tres veces; lo que nos hace suponer que no se mantuvo la continuidad de propósitos y esfuerzos. Además, es probable que diversos factores hicieran que no se pudieran cumplir del todo.

En ese sentido tenemos, al menos, un indicio. Veinticinco años después el gobernador don Alonso Fernández de Heredia, refiriéndose al estado de la villa, fuerte y presidio de San Felipe de Bacalar, dice que debería hacerse iglesia de piedra, "que nunca la ha habido sino de paja", y que ha contribuido con 1000 pesos y que se aprontan los materiales para la construcción. ${ }^{1}$

\section{Entorno histórico-social}

Para comprender mejor la situación tan deteriorada de las iglesias de los pueblos de indios de Yucatán, es conveniente que nos refiramos a la gran crisis que se produjo en la provincia en la década de 1720, y, también, de paso, mencionar el sistema de servicios personales y repar-. timientos a que estaban sometidos los indios.

Entre 1722 y 1727 se produjo en Yucatán una hambruna que, según algunas fuentes, causó 17000 muertos entre los naturales. ${ }^{2}$ Según se

1 AGI, "México 3099". El gobernador de Yucatán a don Julián de Arriaga. Mérida, 28 de abril de 1759.

2 Esta cifra se cita en varios documentos del legajo "México 891", AGI; especialmente en carta del gobernador don Antonio de Figueroa a S. M., de 7 de marzo de 1727, en que da cuenta del hambre padecida en la provincia por falta de maíz, la mortandad cle 17000 "naturales", las providencias aplicadas. Otra es de los ministros del Tribunal de Indios de Yucatán, a. S. M., de $1^{\circ}$ de julio de 1728. 
puede reconstruir de los diversos documentos que iremos citando, la situación probablemente se originó del descontrol producido por la supresión súbita y total en 1722 de los servicios personales y repartimientos de los indios, que vino a desarticular todo el sistema de producción de bienes de consumo y exportación.

De acuerdo con esta forma de trabajo forzado los indios trabajaban por semana para los españoles, pagándoseles menos que en el mercado libre de trabajo. La prohibición la obtuvo el obispo doctor don Juan Gómez de Parada. Luego de realizar su visita pastoral en 1721, y vex los abusos y excesos cometidos contra los indios por el servicio personal y los repartimientos a que se les sometía, envió a España al eclesiástico don Luis Coello, que lo había acompañado en la visita como intérprete y notario, para que gestionase en su nombre las medidas necesarias en favor de los indios. Así se emitió la disposición de 28 de noviembre de 1722, suprimiendo los servicios personales y repartimientos, dándole al obispo comisión exclusiva para aplicar las medidas por encima de la autoridad del gobernador, que era don Antonio de Cortayre.

Investido de esa autoridad el obispo procedió a aplicar la supresión. Según dicen los documentos - probablemente en forma interesada, ya que buscaban la restitución-, los indios se negaron a ir a trabajar con los españoles, incluso si se les pagaba, y aún no pagaban sus contribuciones. Los ministros del Tribunal de Indios, en su carta antes citada, califican las disposiciones de "impracticables y perniciosas" y les atribuyen, con exclusividad, la culpa por él pasada. Según ellos, la provincia sólo produce - deben estarse refiriendo a la exportación- algodón y cera, los indios "... son los precios operarios porque lo inculto, áspero y montuoso de la tierra, y falta de telares, no permite su beneficio a los españoles, y sólo se conforma con la robustés de sus naturalezas..."

Hay que reconocer que, al menos en parte, es contradictorio lo que afirman, ya que el hambre no podía provenix de la supresión de los repartimientos de patíes y cera. Lo que sí produjo esto fue una súbita disminución de los productos de exportación hacia Veracruz, y que los españoles se encontraran con que no tenían nada que darles a los comerciantes que les llevaban produtos importados. La baja en la producción de maíz fue lo que produjo el hambre, que hizo crisis entre 1724 y 1726

Lo cierto fue que las protestas y reclamos del gobernador y de atras autoridades hicieron que se revocara la comisión al obispo, pasando al gobernador la aplicación de la prohibición, en 1725. El nuevo gobernador, Antonio de Figueroa, hizo conducir bastimentos a costa de 
la Real Hacienda, desde Veracruz, y personalmente se encargó de su reparto. Además, según dicen los ministros del Tribunal de Indios, "aplicó exemplares castigos" a los indios que habían cometido excesos -que se habían negado a obedecer a las autoridades civiles y que sólo segufan lo que decía el obispo-, "poniendo en el último suplicio a aquellos cuios execrables delitos les constituían justamente acreedores de él". Además hizo que en muchos pueblos se reedificaran las norias "que tenían abandonadas la nativa ociosidad de sus perezosos ánimos", facilitando las mulas necesarias. Aparentemente los indios habían resistido el trabajar apoyándose en lo dispuesto por el obispo.

La postura del gobernador Figueroa es demostrar al rey que es necesaria las reimplantación de los servicios personales, simplemente evitando abusos y excesos contra los indios -y así declaran en unos autos diez indios y españoles, cuyo testimonio acompaña en carta de 14 de febrero de 1729-, considerando, además, que deben reducirse los repartimientos llamados de paties y cera de los gobernadores, a lo que cada vecindario puede; debiéndose prohibir el de algodón, continuar el de molenderas de maíz y disminuir los capitanes de guerra.

Así pues, en la década de 1720 Yucatán había pasado por una grave crisis que había, momentáneamente, afectado toda la estructura del trabajo compulsivo de los indios para los españoles; que había producido una gran escasez de maíz con gran cantidad de muertos, aunque quizás no tantos como apuntan los documentos.

IV. Obras que se realizaron en las dos iglesias

\section{A. Iglesia de Espitia}

Según el Catálogo de construcciones religiosas del Estado de Yucatán, ${ }^{3}$ la iglesia se fecha a principios del siglo xvir o principios del xvin, por la presencia de las torres sobre la fachada principal asi como su arquitectura general. Ahora podemos fecharla definitivamente como posterior a 1738 .

De acuerdo con el gobernador, esta iglesia era necesario sacarla de cimientos y se haxía de calicanto, con "techumbre de madera y bovedillas", según la "obra practicada en aquel país y tenida por la mejor".

3 Formado por la Comisión de Inventarios de la Cuarta Zona, 1929-1933 (México: Secretaría de Hacienda y Crédito Público, Dirección General de Bienes Nacionales, 1945,2 vols), I, pp. 175-8. 
El obispo nos completa la información de que la iglesia se había incendiado el 3 de mayo, la destrucción debió ser prácticamente total, pues se requería hacerla de nuevo.

Ambos coinciden en decir que para el partido de Espita no se requería, para la construcción, ayuda de indios de otras jurisdicciones. Sólo se relevó a los indios, según dice el gobernador, "de las cargas de milperías del Capitán y de otros particulares, durante dicha fábrica; aunque el vecindario de Valladolid se sirve de algunos indios de aquel partido, precediendo aviso se los señalará de otros pueblos durante la obra".

\section{B. Iglesia de Mama}

Según el catálogo citado, ${ }^{4}$ el templo fue probablemente construido "a fines del siglo xvI, aprovechando para presbiterio la primitiva capilla abierta”. En Mama había convento desde 1612, con título de vicaría en 1617 .

No sabemos con exactitud cuándo se comenzó, pero ya estaba avanzada, pues si bien el gobernador sólo habla que debe "proseguirse", el obispo dice que "es necesario ponerle la última mano por hallarse del todo descubierta". Además hace referencia a las "dificultades" que había visto durante su visita pastoral, de las que informó al fin de ella, y que ahora se habían vencido gracias a la colaboración del gobernador. Estas dificultades estaban probablemente relacionadas con la corta feligresía que entonces tenía Mama, que habían obligado a suspender la obra.

El gobernador informa que la iglesia sería de bóveda, "según la disposición de su fábrica", y que para terminarla se habían señalado trabajadores indios de los otros partidos inmediatos "sin perjudicar la distribución del servicio".

\section{EL DOCUMENTO}

Archivo General de Indias, Sevilla. México. Legajo 892.

Señor.

/fo 1 / - En vista de la representación, que hice a Vuestra Magestad en carta de 22 de Abril de 1736 sobre el reparo, que necesitan las yglesias de esta prouincia, que en gran parte se

4 Ibid., I, p. 289. 
hallan cubiertas de paja, el arbitrio, que ofrezi sin perjuizio de la real Hacienda ni grauamen de los encomenderos, la necessidad que expuse de Yndios aplicados a este trabajo y lo yndispensable del aliuio por lo respectivo a seruicios de otra naturaleza, que pudieran embarazarles el de estas obras se siruio Vuestra Magestad mandar que poniendome de acuerdo con el Governador desta prouincia informassemos vno, y otro el medio, que pareciesse mas practicable, sin perjuicio de lo que Vuestra Magestad tiene resuelto por punto general en Cedula de 1 de Julio de 1731, que dio regla a los reparti/fo $1 \mathrm{vq} /$ mientos, y trabajos / de los Yndios, despues de varias contestaciones, que passaron sobre estte assumpto: y cumpliendo por mi parte, con lo que Vuestra Magestad me preuiene, devo decir, que sin embargo de la citada representacion, que hize, no perdi de vista la primera orden expedida por Vuestra Magestad en 18 de diziembre de 1734, ni la oblicación que me esta impuesta por el derecho, y disposiciones del santto Concilio muchas vezes repetida por Vuestra Magestad en sus leyes y cedulas, en cuia conformidad trate con el expressado Governador la necesidad de poner la vltima mano a la Yglesia de Mama por hallarse de el todo descubierta, y no auer donde celebrar aun con corta decencia el Santo Sacrificio de la Missa; y auiendo encontrado en estte Ministro la disposicion competente para que se me apromptassen yndios de los Partidos

/f9 $\mathbf{2}^{\circ} /$ comarcanos por ser cortta la feligresia / de la citada Parroquia he venido a reconocer con el tiempo y la experiencia, que siempre, que se halle el mismo deseo, y aplicacion a estte assumpto se podra conseguir practicando las misma prouidencias y no emprendiendo la reedificacion de muchas yglesias juntas; sino que se trabaje al mismo tiempo en dos, o tres y no mas, lo que será mas suaue para los Yndios, y de ningun modo perjudicial a la referida orden de 1 de julio de 31 . aunque no tan prompto por la necesidad de executarse en succesion de tiempo. AI presente ocurre el reparo de la yglesia de Espita, que se quemó el dia 3 de Maio, para, lo que se han tomado las mismas prouidencias con la diferencia de no necessitarse de auxilio estraño por no ser dilatado el partido; sino de la xeleuacion de cargas y seruicio, en que igualmente me he puesto con el Gouernador de a acuerdo. 
- La regla, que se ha podido tomar todas las circunstancias de el Pais, y practica de las ordenes de V.M. es aliuiar enteramente a los Yndios de los Partidos en que huviere obra, de todos los mandamientos, de milpa, y demas seruicio, assi a fauor de el capitan a Guerra, como, de qualquiera otro particular ya sea para trabajar en el campo, o ya para assistir en casas particulares de las ciudades, o villas convezinas, reemplazandose la falta que hicieren estos, con Yndios de otros pueblos lo que no sexá dificultoso: y por lo tocante a Atalaieros, Correos, y salineros, disponer se reduzga el numero a lo mas cortto, cargandolo en la misma forma sobre el restto de la capitania de modo, que, si pudiere conseguirse, queden con ninguno, o mui poco trabajo los pueblos ocupados en el edifizio de su yglesia cabezera; para, lo que me pareze con/fo $3 \%$ veniente, quitar en este caso / todo el arbitrio a los capitanes, reseruandolo al superior gouierno, mientras durare el edificio de modo, que no puedan exceder en el numero de Auisos, salineros, ni atalieros; debiendo asegurar a Vuestra Magestad que ninguna precaucion sera inutil ningun aliuio sobrado, en atencion a el horror, que los Yndios tienen a toda fabrica; por lo que juzgo mui precisso animarles a la de sus yglesias con estas inmunidades, $y$ aun maiores si fuese possible y al mismo tiempo quitar a los curas toda ocasion de discordia con los capitanes para que, no resulte de el edificio material la ruina espiritual de los pueblos, y por otra parte pareze justo, que haciendo ellos el todo o la maior parte de el gasto no se les ofresca ocasion de algun desabrimiento.

- Auiendo expressado a vuestra magestad en el informe que hice a fin de la visita con / ocasion de darlo de el estado de la Yglesia de Mama, que por medio de el actual Governador se auian vencido las díficultades, que por entonces ocurrier on y reflecionando que ha tenido en ellas mucha parte su buen deseo, y estrecha, correspondencia, que professa con migo, cuia especial razon pudo influir en la extension de los arbitrios debo preuenirme para lo futuro suplicando a V.M. se sirua dar regla fija para lo de adelante en la conformidad, que lleuo expresado de que no disentira el Governador en su informe segun, lo que en execucion de la Real cedula hemos conferido, como tambien que la prouidencia de releuar los. 
partidos, sin darles aiuda de otros, se entienda den los de 200 mantas, y de ay arriba; y que, a los que no llegasen a este

/f? 4\%/ numero se les proporcione de otros / pueblos competente socorro, con la calidad, de que los que siruieren, como semaneros, sean pagados, y mantenidos: cuia resolucion deseo con la maior expression hecho cargo, de que estas fabricas han de durar a lo menos 20 años, en los que segun la prouidencia comun se mudara tres vezes el gouierno que es quanto puedo exponer a Vuestra Magestad en estte punto, esperando entretanto la resolucion, que en vista de todo se dignare tomar para exercicio de mi imbiolable obediencia. Nuestro Señor guarde la real Catholica Persona de Vuestra Magestad los muchos años que la christiandad ha de menester.

Merida de Yucatan, y Julio 14 de 1738.

Señor.

Francisco Obispo de Yucatan.

/ rúbrica /

/Al dorso/ Yucatan a su Magestad 14 de Julio, de 1738.

Recibida en 17 de Septiembre de 1739.

El Obispo. 